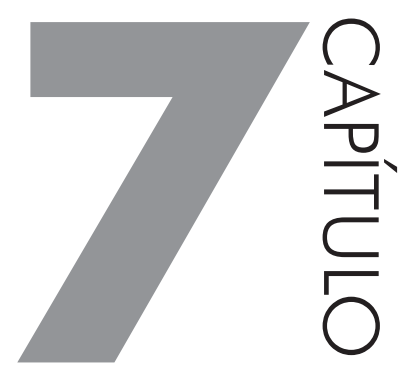

\title{
O DITONGO /ei/ NA FALA DE SÃO TOMÉ
}

\section{RAPHAELA RIBEIRO PASSOS}

\section{INTRODUÇÃO}

Pesquisas sobre variedades do Português falado como Língua 1 ou Língua 2 em diferentes áreas da África têm demonstrado haver uma série de convergências entre elas e o Português do Brasil (PB), o que levou alguns linguistas a considerarem a existência de um continuum afro-brasileiro (PETTER, 2007; AVELAR; GALVES; 2014), conforme já explicitado na Apresentação deste livro, e que vem sendo confirmado em diversos estudos sobre a concordância nominal e a verbal, entre os quais Brandão; Vieira (2012), Brandão (2013), Vieira; Bazenga (2013), que focalizam o Português de São Tomé (PST), em contraste com o PB.

Neste estudo ${ }^{1}$, realizado com base nos pressupostos teórico metodológicos da Teoria da Variação e Mudança (WEINREICH; LABOV; HERZOG, 1968), pretende-se observar o comportamento do ditongo /ei/ em contexto medial e final de vocábulo na variedade urbana do Português de São Tomé, isto é, se esse diton-

1 Este texto apresenta, na íntegra, alguns trechos da dissertação (Passos, 2018) que deu origem ao presente capítulo. 
go se mantém como [ej] - como em af[ej]ção -, se sofre monotongação - [e], como em solt[e]ra e fal[e] - ou, ainda, se concretiza como [ej], como em d[ej]xa, a exemplo do que ocorre no Português Europeu (PE), que serve de norma de referência ao PST.

Com base nos resultados obtidos, objetiva-se, ainda, verificar não só se, nesse particular, há convergências entre as variedades santomense e brasileira, mas também se determinadas ocorrências se devem a uma possível influência do Forro, o crioulo mais falado em São Tomé. Para tanto, parte-se de amostras selecionadas de entrevistas com falantes da comunidade urbana de São Tomé, extraídas do Corpus VAPOR, do Centro de Linguística da Universidade de Lisboa, e realizadas por Tjerk Hagemeijer em 2009.

Para o desenvolvimento deste estudo, fazem-se observações sobre os ditongos em Português (seção 2), seguidas, na seção 3, por comentários sobre alguns estudos que abordam o ditongo /ei/ no PB (3.1) e no PST (3.2). Na quarta seção, apresentam-se os procedimentos metodológicos que nortearam o trabalho e na quinta, expõem-se os resultados da análise da monotongação de /ei/ no PST em contexto medial (5.1) e final de vocábulo (5.2). Na sexta seção, apresentam-se as considerações finais.

\section{OBSERVAÇÕES SOBRE OS DITONGOS DECRESCENTES EM PORTUGUÊS}

Para tratar da questão, selecionaram-se estudos de Câmara Jr. (2011 [1970]), Bisol (1989, 1994, 2012) e Mateus; d'Andrade (2000), embora também tenham focalizado a questão Callou; Leite (2009 [1990]), Gonçalves; Costa (1995), Gonçalves (1997) e Silva (2014).

Segundo a definição de Câmara Jr. (2011[1970], p. 46), o ditongo ocorre "quando a vogal, em vez de ser o centro da sílaba, fica numa de suas duas margens, como as consoantes. O resultado é uma vogal modificada por outra na mesma sílaba e constitui-se o que se chama o ditongo". Nessa posição, há forte neutralização e o quadro do sistema vocálico se resume apenas à oposição entre a vogal alta posterior e a anterior, como nos exemplos pai/pau e sei/seu.

Câmara Jr. levanta ainda o questionamento sobre o fato de a vogal assilábica ser, na verdade, uma consoante no Português, devido ao funcionamento similar entre esses dois elementos. Ao autor parece melhor considerar tal segmento como vogal, argumentando que, após ditongos, é possível encontrar o /r/ brando, que, em português, só existe depois de vogais (dinheiro, costureira, Europa etc.).

Ao tratar a estrutura da sílaba, Câmara Jr. volta a descrever mais detalhadamente os ditongos. Partindo do conceito de sílaba como "um movimento de as- 
censão, ou crescente, culminando num ápice (o centro silábico) e seguido de um movimento de decrescente, quer se trate do efeito auditivo, da força expiratória ou da tensão muscular" (p. 53), o autor conclui que, por suas características, a vogal é normalmente o centro da sílaba em português. Assim, "a estrutura da sílaba depende desse centro, ou ápice, e do possível aparecimento da fase crescente, ou da fase decrescente, ou de uma e outra em volta dele, ou seja, nas suas margens ou encostas" (p. 53).

A proposta de representação para o centro da sílaba é V, e para os elementos marginais, $\mathrm{C}$, resultando em alguns possíveis padrões silábicos para o português. De acordo com as possíveis organizações silábicas, surge o questionamento de como classificar a sílaba composta por um ditongo.

Os denominados alofones assilábicos, ou seja, as vogais altas /i/ e /u/ dos ditongos decrescentes, funcionam na sílaba como a parte decrescente, assim como a consoante /l/ e os arquifonemas /R/, /S/ e /N/. Entretanto, embora funcionem como uma consoante, possuem natureza vocálica, dando então origem ao questionamento anteriormente mencionado sobre sua classificação, se a sílaba com ditongo seria do tipo CVC ou do tipo CVV. A principal diferença entre as duas representações é que a primeira se refere a uma sílaba travada, enquanto a segunda, a uma sílaba livre com núcleo ramificado.

Câmara Jr. apresenta três argumentos em defesa da segunda representação: (i) o processo de monotongação, amplamente difundido em português; (ii) a variação livre na divisão silábica no contexto vogal seguida por vogal alta em sílaba átona, como em vaidade (vai-da-de va-i-da-de); (iii) a possível produção de um /i/ assilábico como /e/ e um /u/ assilábico como /o/ (como em papaê). Interpretando, pois, a vogal assilábica como $\mathrm{V}$, surge o problema de distinguir o número de sílabas do vocábulo com ditongo, como, por exemplo, no caso de "peito". Como determinar que se trata de um dissílabo e não de um trissílabo é uma questão que se apresenta e para a qual Câmara Jr. propõe como solução o caráter de emissão reduzida da vogal assilábica, o que a caracterizaria como uma semivogal.

Além desse problema, há ainda a questão sobre a real existência de ditongos em português, pois há a dúvida se essas sequências não poderiam ser consideradas como hiato, constituído por uma sequência de duas vogais silábicas. A descrição comum gramatical não é satisfatória para Câmara Jr., pois opõe pares como "sai" e "saí", que não podem ser considerados pares opositivos mínimos já que não possuem a mesma sequência acentual. O autor apresenta, então, alguns exemplos em que a sequência acentual é a mesma, como o par "riu" e "rio" (/riu/ e / $\mathrm{ri}^{\mathrm{u} / \text { ) }}$ na fala do Rio de Janeiro, o que demonstra, com a oposição, portanto, a existência do ditongo. Com base no exposto, Câmara Jr. enumera 11 ditongos decrescentes, entre os quais /ei/. 
Bisol (1989) apresenta uma análise sobre a estrutura dos ditongos e seus diferentes tipos, que, mais tarde, seria por ela revisitado (1994; 2012). Nesse estudo, em que analisa os ditongos com base na teoria da sílaba, a autora define sílaba "como um objeto multidimensional de sequência de segmentos, cujos constituintes são organizados hierarquicamente” (BISOL, 1989, p. 186). Na Figura 1 é apresentada a mencionada organização hierárquica.

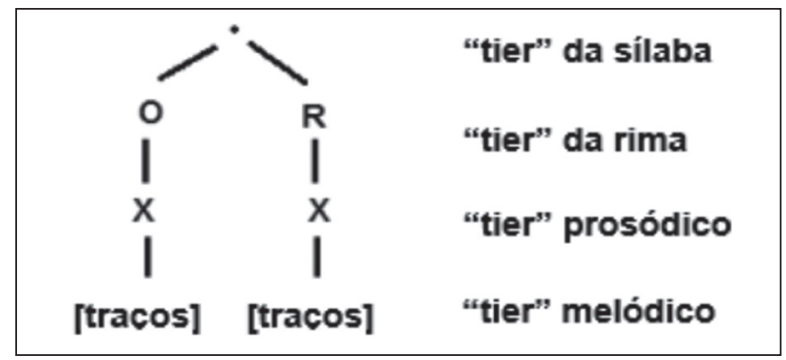

Figura 1 Organização hierárquica da sílaba (BISOL,1989. p. 186)

O que é definido como tier na figura acima são sequências de unidades. Nesse diagrama, é no tier prosódico, representado por X, que está o chamado espaço temporal ao qual correspondem os elementos da sílaba, como uma consoante seguida por uma vogal, por exemplo. Acima desse nível, temos o onset e a rima da sílaba, que se ligam aos constituintes prosódicos que estão no nível hierárquico abaixo (as consoantes e vogais da sílaba)

Outro ponto importante é a distinção entre sílabas leves e pesadas, sendo as sílabas leves compostas por rima simples, de um só segmento, e as pesadas compostas por rima ramificada, com mais de um segmento. Os respectivos diagramas são apresentados na Figura 2.

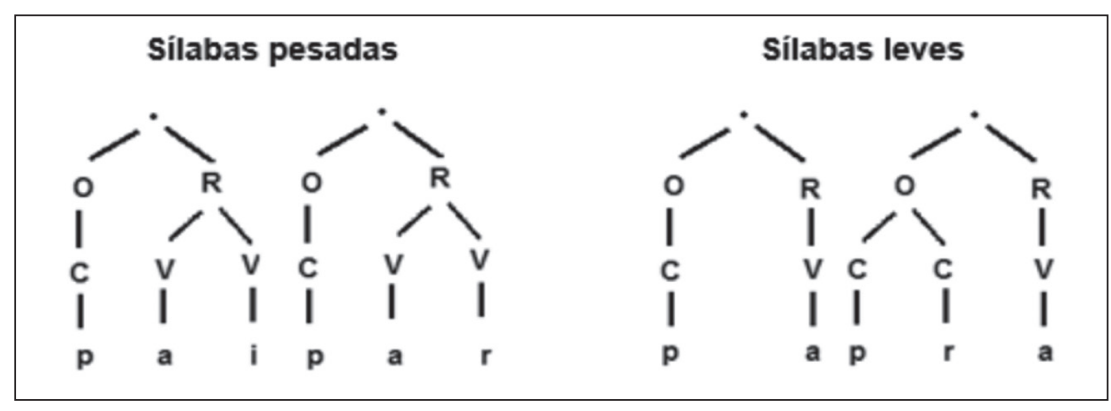

Figura 2 Diferença entre sílaba pesada e sílaba leve (BISOL,1989. p. 187)

A partir de tais apontamentos e de outros princípios norteadores de suas análises, Bisol levanta a discussão sobre dois tipos de ditongos: o verdadeiro e o falso. Nas palavras da autora, a distinção se dá da seguinte maneira: "o ditongo 
pesado, o verdadeiro, [é] associado a duas posições no "tier" da rima, e o ditongo leve, associado a uma só posição. O primeiro constitui uma sílaba complexa e tende a ser preservado; o segundo constitui uma rima simples e tende a ser perdido" (BISOL, 1989, p. 189-190).

Alguns exemplos apresentados para ilustrar o ditongo verdadeiro, ou pesado, são "p[aw]ta" e "r[ej]no", palavras nas quais o ditongo tende a ser preservado e no âmbito do qual dificilmente ocorreria o fenômeno da monotongação. Já exemplos de palavras com ditongos falsos, ou leves, seriam "p[ej]xe" e "f[ej]ra", vocábulos cujo ditongo tende a ser perdido, na fala, com alta frequência.

Com base nas observações de Bisol, pode-se considerar o processo de monotongação do ditongo [ej], aqui estudado, como um fenômeno, de fato, passível de ocorrer e presente na língua, devido aos fatores estruturais que o compõem, principalmente no caso dos chamados falsos ditongos. Além disso, Bisol também apresenta observações fundamentais para a definição de variáveis a serem aplicadas para estudos sobre a queda desses ditongos, quando analisa os contextos em que o falso ditongo pode estar inserido. Um desses contextos é aquele em que, no segmento subsequente ao ditongo, se encontra uma consoante palatal. Segundo Bisol, o acréscimo ou apagamento da semivogal diante de uma consoante palatal pode ser feito sem que haja qualquer prejuízo para o significado da palavra. Em suas palavras: "o glide é sempre consequência da palatal. Sua forte relação com a consoante palatal indica que ele se forma no tier melódico, o qual, por sua vez, também é um componente organizado hierarquicamente, com traços ligados a um centro comum, o tier da raiz" (BISOL, 1989, p. 191).

Assim, nesse contexto, o ditongo seria, na verdade, um espraiamento do traço [+alto] da palatal subsequente, não presente, portanto, na estrutura subjacente. Outro contexto que criaria um falto ditongo seria quando há a presença de um tepe no segmento subsequente. Nesse caso, como no anterior, a perda da semivogal não leva à criação de pares mínimos e o sentido da palavra é mantido.

Bisol apresenta duas hipóteses para justificar que o ditongo seguido por tepe é, na verdade, um falso ditongo: uma seria por metátese, com espraiamento de traços de outros segmentos, gerando a semivogal, e a outra por inserção, considerando a escala de sonoridade do tepe, que, dentre as líquidas, consoantes que possuem certas características vocálicas, seria o segmento mais próximo da escala de sonoridade das vogais.

Entretanto, ambas as hipóteses apresentam problemas e não são capazes de explicar de todo como se daria a inserção da semivogal nesse contexto. Como as hipóteses apresentadas não dão conta de oferecer uma justificativa completa, Bisol apresenta mais um dado para reforçar a defesa de que, diante de tepe, há na verdade um falso ditongo. Esse dado é uma comparação do processo de monoton- 
gação dos ditongos decrescentes diante de consoante palatal e diante de tepe. Nos dois contextos, os índices de apagamento da semivogal são altos, atingindo percentuais de $76 \%$ e $81 \%$, respectivamente, com pesos relativos de .89 em ambos os casos (BISOL, 1989, p. 197). A alta frequência da monotongação leva a autora a concluir que, assim como quando seguida por palatal, a semivogal do ditongo diante de tepe não está presente na estrutura subjacente na sílaba.

Sobre a oposição entre ditongos verdadeiros e ditongos falsos, a autora conclui com a seguinte sistematização: "ditongos formados no nível mais abstrato, tier da rima, tendem a ser preservados; ditongos mais próximos à superfície, formados no tier melódico, podem ser perdidos" (BISOL, 1989, p. 221).

Bisol revisita o tema posteriormente, em dois momentos: em 1994, em estudo no qual, baseada em análises estatísticas, apresenta mais argumentos para defender a existência do ditongo fonético em oposição ao fonológico, tratando, em especial, do falso ditongo diante de consoante palatal; e, em 2012, focalizando o ditongo diante de tepe.

No primeiro desses trabalhos, são apresentados resultados da análise de uma amostra que contempla sete informantes da cidade de Porto Alegre, mais especificamente os resultados para a variável contexto subsequente ao ditongo, variável que interessava ao estudo e que estava constituída pelos fatores consoante palatal e tepe em oposição aos demais fatores (labial, velar, alveolar e vogal). Os resultados apresentados indicam claramente que a queda da semivogal é extremamente favorecida quando há, no contexto seguinte, a presença de uma palatal ou do tepe (BISOL, 1994, p. 124).

Partindo desses resultados, ela volta a defender a ideia de que, nesses contextos específicos, o ditongo não está presente na estrutura subjacente da sílaba. Duas observações importantes são feitas: (i) apenas os ditongos [aj] e [ej] que ocorrem diante de consoante palatal na sílaba seguinte podem sofrer monotongação, independentemente da tonicidade da sílaba; (ii) há palavras que, na fala, apresentam o ditongo, embora este não conste de sua representação gráfica ("fechar”, alternando entre $f[e]$ char e f[ej]char). Segundo Bisol:

Não há como interpretar inserção do glide de um lado e apagamento do outro, em se tratando de contexto similar. Essa é a evidência mais forte que nos leva a admitir que a forma subjacente das palavras [com e sem ditongo diante de consoante palatal na sílaba seguinte] não possuem a vogal alta responsável pelo glide. São palavras de estrutura subjacente de uma vogal só, nessa posição. (1994 p. 126, 127).

Assim, a teoria de que o glide, nesse contexto, surge como um espraiamento do traço vocálico da consoante palatal, que é uma consoante complexa, é refor- 
çada e mais uma vez defendida por Bisol. A autora conclui que, se o glide que aparece no contexto é um glide derivado, então o ditongo formado também é um ditongo derivado, ou seja, um falso ditongo.

BISOL (2012) é um adendo ao trabalho anterior, e trata do segundo contexto que foi introduzido, mas não analisado, de geração de um falso ditongo com a presença de um tepe como segmento subsequente ao ditongo. Para a análise, Bisol parte das características das consoantes líquidas, ou seja, do fato de estas serem segmentos classificados como aproximantes que possuem o traço vocálico e que constituiriam, juntamente com as vogais, uma única classe, como aproximantes ou como segmentos vocálicos.

Dessa forma, assim como no caso de uma palatal no contexto seguinte, com um tepe nessa posição a formação do ditongo se daria por espraiamento do traço vocálico do tepe. Algumas evidências são apresentadas para sustentar essa hipótese, como o fato de que, no PB, depois de vogal, a líquida lateral (normalmente realizada como velar ou dorsal) geralmente se apresenta como glide posterior [w] (me[w], por $m e l$ ), mas diante do /S/ plural, o glide passa a coronal, em consonância com o traço coronal de /S/, como em $\mathrm{m}[\varepsilon j] \mathrm{s}$. Outra evidência seria encontrada ao se observarem outras línguas, nas quais as líquidas são realizadas como glide, como, por exemplo, no cibaeño, um dialeto do espanhol (carta-caita). Por fim, há ainda o que se observa no processo de aquisição de linguagem pelas crianças, que costumam realizar as líquidas como uma vogal alta. Todas essas evidências reforçam a ideia central de que o ditongo, em contexto de tepe subsequente, é resultado do espraiamento do traço vocálico do tepe, e, portanto, um falso ditongo.

Cabe, ainda, mencionar, tendo em vista os objetivos deste estudo, como o ditongo se comporta no PE.

Mateus; d'Andrade (2000), na descrição do sistema fonológico do PE, focalizam a estrutura da sílaba, baseados no padrão culto de Lisboa, e observam que o PB e o PE possuem praticamente o mesmo quadro de sete vogais tônicas, como no PB. No PE, além dessas vogais, há ainda o [], cujo contraste com [a] "seria apenas aparente, uma vez que [e] tônico é uma realização alternativa de outras vogais tônicas em determinados contextos" (p. 19): (i) antes de consoante palatal (t[e]lha - "telha"); (ii) antes de glide palatal (l[e] - "lei"); (iii) antes de consoante nasal (c[e]ma - "cama").

Devido à possibilidade de ocorrência de [e] antes de glide palatal, há no PE um ditongo que não ocorre no PB, o [ej]. Essa é uma das poucas diferenças entre as duas variedades no quadro de ditongos decrescentes tônicos apresentado por Mateus; D’Andrade (2000), que oferecem, como exemplo, as realizações de "quei-

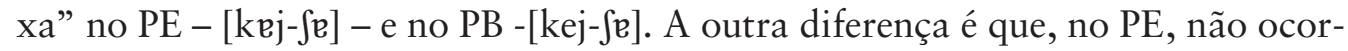
reria o ditongo decrescente $[\mathrm{ow}$, que, no $\mathrm{PB}$, resulta da realização, em final de sílaba, da lateral como um glide (volta). 
Sobre o fenômeno da monotongação dos ditongos /ei/ e /ai/ no PE, Cunha (1986) afirma ser esse um processo antigo, já registrado pela grafia desde Os Lusíadas, com os exemplos "pexe" e "baxa", sendo temerário, pois, atribuir esse fenômeno a inovações brasileiras. Sobre o ditongo /ou/, o autor afirma ser sua monotongação comum no PE desde o século XVII, não sendo também o fenômeno geral apenas no Brasil.

Cintra (1983) volta-se para a questão dos ditongos /ei/ e /ou/ e sua variação com a forma monotongada e, com base na distribuição dessas variantes, constitui duas isófonas utilizadas por ele para delimitar as áreas linguísticas portuguesas. Segundo sua divisão, as possíveis realizações da forma ditongada /ou/ são características dos dialetos setentrionais, já a variante monotongada tipifica os dialetos centro-meridionais. No caso de /ei/, a variante ditongada se apresenta nos dialetos setentrionais e em uma subárea dos dialetos centro-meridionais, e a variante monotongada nos dialetos centro-interior e sul.

Em suma, no PB e no PE, há a ocorrência de ditongos que podem sofrer monotongação, gerando duas variantes possíveis. Constitui-se como um dos objetivos deste trabalho investigar se no Português de São Tomé tal processo também ocorre e que fatores o condicionam.

\section{ESTUDOS SOBRE O DITONGO /ei/}

\subsection{No Português do Brasil}

No âmbito do PB, diversos foram os estudos que focalizaram a monotongação de /ei/. Dentre eles, citam-se os de Ribeiro (1990) referente ao Sudoeste do Paraná, que observou apenas a atuação de fatores estruturais; o de Paiva (1996), sobre a fala do Rio de Janeiro, retomado em 2011; Lopes (2002), realizado em Altamira, Pará, em que, diferentemente dos demais estudos, uma das variáveis relevantes para a atuação da regra foi o nível de escolaridade do falante; Pereira (2004), que verificou o apagamento de semivogais em ditongos orais na Região Sul do país, mais especificamente, em Tubarão, Santa Catarina; Toledo (2011) que tratou especificamente da monotongação de /ei/ na fala de Porto Alegre, com o objetivo de verificar que contextos linguísticos a condicionam, observando, em especial, a possível atuação de fatores de natureza morfológica.

Tendo em vista a convergência de resultados neles observados, comentam-se, nesta seção, os estudos de Paiva (1996, 2011), apresentando-se, ao final, um quadro comparativo dos resultados obtidos pelos demais autores aqui citados, independentemente das especificidades de cada análise. 
Paiva (1996) analisou os ditongos /ou/ e /ei/ com base em entrevistas de fala espontânea realizadas com moradores do Rio de Janeiro, distribuídos por sexo, idade e faixa etária, estabelecendo assim as três variáveis sociais que seriam controladas. Além delas, verificou a atuação de quatro variáveis estruturais: extensão da palavra, contexto subsequente, tonicidade da sílaba e posição no vocábulo (sufixo ou radical). A posição da sílaba no vocábulo, medial ou final, não foi levada em conta, pois, em seu entendimento, em posição final, o ditongo /ei/ sempre seria mantido e /ou/ sempre seria monotongado.

Sua hipótese de partida era que a monotongação de /ei/ é condicionada principalmente por fatores linguísticos. A autora levantou um total de 3133 dados, sendo 2111 do ditongo [ej]. Os resultados encontrados para o ditongo indicaram que, conforme a hipótese inicial, apenas fatores estruturais estariam atuando sobre o fenômeno, já que nenhuma variável social foi selecionada na análise realizada: mostraram-se atuantes o contexto subsequente, a extensão da palavra e a posição no vocábulo.

Para a variável contexto subsequente, de acordo com o ponto de articulação, os fatores que se mostraram favorecedores da monotongação foram as velares (P. R.: .89), embora a autora ressalte que a alta frequência do vocábulo "manteiga" deveria ser o gerador desse resultado, já que, em outros vocábulos, o mesmo não ocorreu. Em seguida, vêm e as alveolopalatais (P. R.: .93). Já os demais fatores, dentais, alveolares e vogais, se mostraram inibidores do processo, com pesos relativos de $.15, .27$ e .10 , respectivamente.

Considerando os fatores referentes ao modo de articulação, o tepe se mostrou altamente favorecedor do processo (P. R.: .99), enquanto as fricativas, embora também favorecedoras, apresentaram um peso relativo mais baixo, .56. Os demais fatores, oclusivas, nasais e laterais, se mostraram inibidores da monotongação, com pesos relativos de $.13, .13$ e .25, respectivamente.

Quanto à extensão da palavra, verificou-se que, quanto maior o número de sílabas, maiores as chances de a monotongação ocorrer. Tanto os fatores polissilábicas quanto trissilábicas apresentaram um P. R. alto, de .71, seguido pelas dissilábicas (P. R.: .67). Por fim, as palavras monossilábicas se mostraram altamente inibidoras da monotongação (P. R.: .07).

A última variável selecionada, posição no vocábulo, demonstrou que ditongos que ocorrem no sufixo são mais sensíveis ao processo de monotongação (P. R.: .61), ao contrário dos que aparecem no radical, cujo peso relativo (. 38) demonstrou que esse contexto é inibidor do processo. Com relação a essa variável, Paiva observa que os resultados podem estar sofrendo interferência de outra variável, o contexto subsequente, uma vez que o sufixo derivacional -eiro se mostrou bastante presente nos dados, ou seja, a presença de um tepe após o ditongo poderia 
estar gerando a queda da semivogal, e não, necessariamente, o fato de a posição ser a de um sufixo.

Em suma, o trabalho de Paiva confirma a hipótese inicial da autora, que constatou que a monotongação do ditongo /ei/ depende basicamente de restrições de ordem estrutural, como o modo e o ponto de articulação do segmento subsequente, sendo favorecido, nesse contexto, pelo tepe e as fricativas, dentre estas as palatoalveolares, e que fatores sociais não estariam interferindo no processo.

Posteriormente, em 2011, Paiva revisita o comportamento do /ei/ no Rio de Janeiro. No estudo, pretendia verificar a atuação da variável tempo sobre o processo, associando análises de tempo aparente e de tempo real em um estudo combinado dos tipos painel e tendência. Esse tipo de análise se deve, segundo a autora, ao fato de que "tendências depreendidas em um estudo do tipo painel são reforçadas pelo estudo da comunidade de fala, observando-se notável sistematicidade e regularidade na trajetória do processo" (p. 32). Para tanto, indivíduos entrevistados no final da década de 1990 foram recontactados para novas entrevistas.

Os resultados encontrados com a comparação das duas amostras parecem sugerir um recuo do uso da variante monotongada. Paiva analisa separadamente os 31 indivíduos que apresentaram um incremento nos anos de escolarização no intervalo entre as duas entrevistas e constata que, na maioria desses casos, houve um declínio tanto em frequência quanto em peso relativo da variante monotongada. Entretanto, ao analisar separadamente também o grupo dos indivíduos que não tiveram alteração nos anos de escolaridade, os resultados parecem sugerir que o recuo da variante monotongada pode não estar relacionado diretamente à escolaridade, já que, nesse grupo, também houve um declínio da queda da semivogal: quatro falantes mostraram nítido recuo de uso da variante monotongada; três apresentaram estabilidade no processo e dois deles um aumento de aplicação do processo.

Paiva destaca que uma possível explicação para essas tendências contraditórias pode ser a influência do item lexical mais recorrente em uma entrevista, pois uma análise mais detida da segunda entrevista desses falantes mostra que a variante monotongada está concentrada em itens lexicais em que a semivogal anterior antecede o tepe, como em dinheiro e feira, contexto em que a realização da variante monotongada se torna praticamente categórica (p. 35).

Considerando tais resultados comparativos entre as duas amostras e os resultados complementares encontrados para indivíduos e para a comunidade, Paiva levanta a hipótese de que haja uma mudança geracional, "com indivíduos mudando ao longo da sua vida e a comunidade se mantendo estável" (p. 37). Assim, os falantes estariam alterando seu comportamento linguístico de maneira a "adequar-se à nova faixa etária" em que se encontram, o que pode ser observado no estudo de tendência, que compara as duas amostras e mostra uma estabilidade do 
processo de monotongação nas duas épocas distintas, sendo a faixa 1 a que mais monotonga e a faixa 3 a que menos monotonga.

Com relação aos condicionantes estruturais, Paiva argumenta que sua importância não pode ser ignorada para a determinação da direcionalidade da alternância [ej]/[e]. O ponto e o modo de articulação seguem sendo os principais condicionantes do processo, sendo o tepe e as fricativas palatais os principais favorecedores da queda da semivogal. Entretanto, a autora observa um avanço do processo no ambiente tepe, o que parece constituir uma mudança já consumada, enquanto para o ambiente de fricativa palatal parece haver um recuo da implementação do processo, demonstrando ser esse um contexto de maior variabilidade na realização da semivogal.

Como se observou no início desta seção, apresenta-se, a seguir, um quadro comparativo dos fatores que se mostraram relevantes para a monotongação de /ei/ nos estudos aqui mencionadas, lembrando que a escolha e a composição das variáveis não obedeceram necessariamente aos mesmos parâmetros.

Quadro 1 Comparação entre os fatores condicionantes da monotongação de /ei/ em seis estudos no âmbito do PB

\begin{tabular}{|c|c|c|c|c|c|}
\hline $\begin{array}{c}\text { Ribeiro (1990) } \\
\text { Sudoeste do Paraná }\end{array}$ & $\begin{array}{c}\text { Paiva } \\
(1996) \\
\text { Rio de Janeiro-RJ }\end{array}$ & $\begin{array}{c}\text { Lopes } \\
(2002) \\
\text { Altamira-PA }\end{array}$ & $\begin{array}{c}\text { Pereira } \\
(2004) \\
\text { Tubarão, SC }\end{array}$ & $\begin{array}{c}\text { Toledo } \\
\text { (2011) } \\
\text { Porto Alegre-RS }\end{array}$ & $\begin{array}{c}\text { Paiva } \\
(2011) \\
\text { Rio de Janeiro-RJ }\end{array}$ \\
\hline $\begin{array}{l}\text { Tipo de silaba: não finais } \\
\frac{\text { Número de silabas: }}{\text { três/quatro. }} \\
\text { Estrutura da } \\
\text { silaba: travadas por/S/ } \\
\frac{\text { Classe do vocábulo: }}{\text { Substantivos/ }} \\
\text { adjetivos } \\
\frac{\text { Contexto fonológico }}{\frac{\text { subsequente: }}{\text { tepe; }}} \\
\text { palatoalveolar }\end{array}$ & 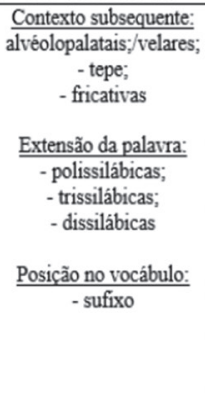 & $\begin{array}{l}\frac{\frac{\text { Localização do ditongo }}{\text { na estrutura morfológica }}}{\frac{\text { da palavra: }}{\text { base }}} \\
\frac{\text { Contexto fonético }}{\frac{\text { seguinte: }}{\text { tepe; }}} \\
\text { consoantes palatais } \\
\frac{\text { Natureza da origem do }}{\frac{\text { vocábulo: }}{\text {-comum }}} \\
\frac{\text { Escolaridade: }}{\text { baixa }}\end{array}$ & $\begin{array}{l}\frac{\text { Monotongação }}{\text { categórica: }} \\
\text { Ressaltando que a } \\
\text { grande maioria dos } \\
\text { dados era composta } \\
\text { por palavras com tepe } \\
\text { no contexto } \\
\text { subsequente }\end{array}$ & $\begin{array}{l}\frac{\text { Contexto seguinte: }}{\text { - tepe }} \\
\frac{\text { Natureza }}{\text { morfologica: }} \\
\text { radical } \\
\frac{\text { Classe de palavras: }}{\text { não-verbos }}\end{array}$ & $\begin{array}{l}\text { Tendência ao recuo da } \\
\text { variante monotongada. } \\
\text { Indicios de mudança } \\
\text { geracional, talvez } \\
\text { vinculada ao incremento } \\
\text { da escolaridade. } \\
\text { Constante atuação de } \\
\text { fatores estruturais: tepe e } \\
\text { fricativa palatal no } \\
\text { contexto subsequente }\end{array}$ \\
\hline
\end{tabular}

Fonte: Passos (2018)

\subsection{No Português de São Tomé}

No PB, há diversos estudos sobre o ditongo /ei/, tanto que, na seção anterior, selecionaram-se apenas alguns deles, de modo a retratar a monotongação em diferentes épocas e áreas do país. 
A situação no que se refere ao PST é bastante distinta. Embora haja alguns estudos no âmbito morfossintático sobre essa variedade, raros são os que recobrem aspectos fonético-fonológicos, conforme observam Brandão; De Paula no capítulo 4 deste livro. Dentre eles, encontra-se o de Silveira (2013), que procede a uma descrição dos ditongos que ocorrem no PST, entre eles /ei/, também focalizado por Passos; Barcelos (2015), no âmbito da Iniciação Científica da UFRJ.

Silveira (2013) buscou investigar, no português vernacular são-tomense, a realização dos ditongos orais e se eles são passíveis de monotongação, como ocorre, por exemplo, no PB, verificando, também, que fatores a condicionariam. O autor parte da hipótese de que, em São Tomé, as realizações dos ditongos não serão as mesmas que no PE, uma vez que, nessa região, concorrem com o português outras línguas crioulas, que não têm ditongos, ou os têm de forma limitada.

Para o trabalho variacionista, realizado com o auxílio do programa Goldvarb 2001, o autor usou um corpus composto por entrevistas de fala espontânea, realizadas entre os anos de 2009 e 2011, totalizando 50 horas de gravações. Na seleção dos informantes, distribuídos por sexo, faixa etária e escolaridade, deu preferência àqueles que fossem naturais de São Tomé e que tivessem pais são-tomenses

Foram controladas, além das variáveis sociais já citadas, as variáveis estruturais classe morfológica do item lexical, posição do ditongo no vocábulo, tonicidade, localização do ditongo na estrutura morfológica da palavra, contexto fonético subsequente e número de sílabas.

O total de ocorrências de ditongos orais encontradas foi de 3017, quase to-

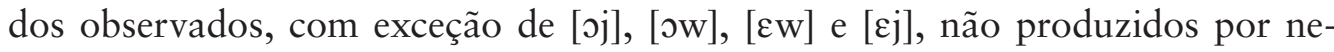
nhum dos informantes. Analisando-os em conjunto, Silveira constatou que em $49 \%$ dos casos (1482 em 3017) houve monotongação. A maioria deles apresentou algum percentual de monotongação, com exceção de /iw/, /uj/, com apenas três ocorrências no corpus: "cuidar", "viu" e "desistiu".

Após a análise em conjunto, o autor focalizou cada um dos ditongos. $\mathrm{O}$ quadro a seguir mostra os resultados encontrados para os diferentes ditongos estudados (além dos ditongos [iw], [uj], explicados anteriormente).

Tabela 1 Percentuais de monotongação dos ditongos no PST (SILVEIRA, 2013)

\begin{tabular}{|c|c|c|}
\hline DITONGO & TOTAL DE OCORRÊNCIAS & PERCENTUAL DE MONOTONGAÇão \\
\hline [oj] & $606 / 3017$ & $35 \%$ \\
\hline$[$ ow] & $588 / 3017$ & $99,5 \%$ \\
\hline$[\mathrm{aj}]$ & $469 / 3017$ & $26 \%$ \\
\hline
\end{tabular}




\begin{tabular}{|c|c|c|}
\hline$[\mathrm{ew}]$ & $387 / 3017$ & $5 \%$ \\
\hline$[\mathrm{aw}]$ & $79 / 3017$ & $11 \%$ \\
\hline$[\mathrm{ej}]$ & $525 / 815$ & $65 \%$ \\
\hline
\end{tabular}

Fonte: Silveira (2013), com adaptações

Para o ditongo /ei/ foram encontrados 815 dados. Desse total, $65 \%$ apresentaram monotongação, o que demonstra ser esse um processo produtivo também nessa variedade. Os resultados indicaram seis variáveis como as mais atuantes para a implementação da monotongação.

Os resultados relativos à variável contexto seguinte, a mais saliente delas, indicaram que os fatores que mais favorecem o processo são, em sequência de relevância, os róticos, com P. R.: .96; as fricativas pós-alveolares (P. R.: .93), as fricativas alveolares, (P. R.: .65); e, com um P. R. neutro, .50, as oclusivas alveolares, na realidade, mais especificamente a oclusiva alveolar surda [t]. Esse último fator chama a atenção pelo fato de que, no geral, em outras variedades do Português, ele se mostrar um inibidor do processo, não havendo relato de casos de monotongação do ditongo /ei/ diante de [t].

Quanto à variável classe de palavra, há desfavorecimento da monotongação quando a palavra é um verbo, com P. R.: .32. São os não verbos que favoreceriam a regra, com P. R.: .80. Silveira observa que, do total de verbos encontrados (275), apenas em 64 houve a montongação, e que esses casos não eram com o ditongo em posição final, mas sim medial, como, por exemplo, nos vocábulos "aproveita", "aleija" e "deixa". Com o ditongo em posição final, como em "falei", não foi encontrado nenhum caso de monotongação. Já dentre as palavras classificadas como não-verbos (460), somente em três delas o ditongo estava em posição final.

Tais observações levam à conclusão de que, embora os resultados pareçam indicar que o fator não-verbo favoreça a queda da semivogal e o fator verbo a desfavoreça, parece ser a posição do ditongo no vocábulo o que realmente está condicionando o processo, tanto que a outra variável selecionada é justamente a posição da sílaba no vocábulo (inicial, medial ou final). Se o ditongo se encontra em contexto medial, é alto o índice de monotongação de /ei/ (P. R.: .81), diferentemente do que ocorre quando está em posição inicial (P. R.: .51, considerado neutra) ou final (P. R.: .03, desfavorecedor).

A última variável estrutural selecionada como relevante, o número de sílabas, demonstrou que o grupo das dissílabas é o maior favorecer da monotongação, com P. R.: .62, seguido pelas polissílabas com P. R. próximo da neutralidade, .53 . 
As duas últimas variáveis selecionadas foram as de natureza social escolaridade e idade. Os resultados demonstraram que quanto maior a escolaridade do indivíduo, menor a probabilidade de que ele realize a monotongação. O P. R. do fator escolaridade alta foi de .27. O grupo dos falantes de escolaridade média apresentou P. R. próximo da neutralidade, .48. Por fim, os menos escolarizados favorecem a monotongação (P. R.: .64).

Já para a variável idade, os resultados indicam que quanto mais jovens forem os falantes, maior a probabilidade de que haja o processo de monotongação. Silveira atribui esses resultados ao fato de os mais jovens serem, geralmente, mais inovadores no uso da língua, enquanto os mais velhos seriam mais conservadores.

Passos; Barcelos (2015) também estudaram esse ditongo, chegando a resultados semelhantes aos encontrados por Silveira. O estudo demonstrou que a variável linguística de maior destaque para a implementação da monotongação é o contexto subsequente, com destaque para as fricativas pós-alveolares e o tepe. Além disso, também foi observada a monotongação diante da dental [t]. Uma divergência encontrada com relação aos resultados de Silveira foi a ocorrência de monotongação de /ei/ em posição final em verbos. Sobre as variáveis sociais, assim como no trabalho exposto anteriormente, escolaridade se mostrou saliente, indicando que, quanto maior a escolaridade do falante, menor a queda da semivogal. Em suma, podem-se observar convergências nos resultados encontrados nos estudos no âmbito do PB e do PST. Em ambas as variedades, os maiores condicionantes do processo de queda do ditongo são os fatores estruturais, principalmente a presença, no contexto seguinte, de um tepe ou de uma fricativa pós-alveolar. A grande diferença entre as duas variedades é que, no PST, a presença de um $[t]$ no contexto seguinte também favorece o processo, enquanto no PB esse fator bloqueia a queda da semivogal. Com relação às variáveis sociais, apenas escolaridade parece ser relevante, com resultados similares nas duas variedades, que apontam que quanto maior a escolaridade do indivíduo, menores as chances de monotongação.

\section{ASPECTOS TEÓRICO-METODOLÓGICOS}

A realização da pesquisa se deu com base nos pressupostos teórico-metodológicos da Teoria da Variação e Mudança (Weinreich, Labov; Herzog, 2006 [1968]) e da Sociolinguística Variacionista desenvolvida por Labov (2008 [1972]; 1994; 2001), que considera, entre outros princípios, a noção de regra variável, dependente da atuação de restrições sociais e linguísticas.

Serviu de base para o levantamento das ocorrências do ditongo /ei/ o Corpus VAPOR, do Centro de Linguística da Universidade de Lisboa, que conta com entrevistas realizadas por Tjerk Hagemeijer em 2009. Todos os informantes, nativos 
de São Tomé, declararam ser falantes de Português como L1 e estão distribuídos por sexo, três faixas etárias ( 18 a 35, 36 a 55 e 56 a 75 anos) e três níveis de escolaridade (fundamental: 5 a 8 anos; médio: 9 a 11 anos e superior: de 12 anos em diante). As gravações, que têm duração média de 25,6 minutos, são do tipo DID (Diálogo entre Informante e Documentador) e versam sobre temas diversos.

Definiram-se, para a análise, realizada com o auxílio do programa estatístico Goldvarb-X, as variáveis clássicas sexo, escolaridade e faixa etária, além da variável comentada anteriormente, frequência de uso de um crioulo (BRANDÃO, 2011), aplicada para averiguar se os indivíduos que fazem uso de uma língua crioula apresentam influências dessa língua ao falarem português. Essa variável está dividida em três fatores: (i) frequência zero ou baixa, para indivíduos que se expressam fundamentalmente em Português; (ii) frequência média, relativa a indivíduos que se expressam em Português, mas têm o domínio de uma língua crioula e a usam eventualmente; e (iii) frequência alta, para indivíduos que falam Português, mas se expressam com maior regularidade com um crioulo.

Com a aplicação dessa variável, buscou-se confirmar a hipótese de que o uso regular do Forro gera influências no Português com relação à produção do ditongo /ei/, uma vez que, segundo Ferraz (1979), o padrão silábico principal do Forro é do tipo $\mathrm{CV}$, seguido dos padrões $\mathrm{V}$ e $\mathrm{CVC}$, que são menos usuais. O autor aponta que, no Forro, a sílaba é aberta na maioria dos casos, e os casos de sílaba fechada seriam uma influência moderna do Português. Assim, ao fazer uso regular do Forro, o falante estaria mais sujeito à monotongação de /ei/.

Além das variáveis sociais apresentadas, foram controladas ao todo cinco variáveis estruturais, definidas com base nos estudos sobre o tema realizados no PB. Foram elas: o contexto antecedente, o contexto subsequente, a tonicidade da sílaba, o número de sílabas no vocábulo e a posição no vocábulo (radical ou sufixo).

$\mathrm{Na}$ análise, foram consideradas duas amostras, uma referente ao /ei/ em contexto medial, outra, em contexto final de vocábulo.

\section{RESULTADOS DAS ANÁLISES}

No levantamento realizado nas 17 entrevistas do corpus que serviu de base para o trabalho, foram encontrados 736 dados do ditongo /ei/, tanto em contexto medial de vocábulo, como em "d/ei/xa", quanto em contexto final em formas verbais, como em fiqu/ei/. Na amostra geral, registraram-se realizações de /ei/ ditongado - [ej] - ou monotongado - [e] -, não havendo ocorrências de [rj], como no PE. Os índices gerais demonstraram que, na variedade urbana do PST, a monotongação de /ei/ é um processo produtivo, com 70,1\% de aplicação, correspondentes a 516 das 736 ocorrências, constituindo, portanto, uma regra variável. 
Em contexto medial, foram levantadas 417 ocorrências do ditongo, e em contexto final, 319. A seguir, apresentam-se os resultados para cada posição.

\subsection{O ditongo /ei/ em contexto medial de vocábulo}

Em contexto medial, o índice de motongação se mostrou maior do que o encontrado na análise conjunta, atingindo $83,7 \%$ dos dados, conforme exposto na Figura 3 e na Tabela 2.

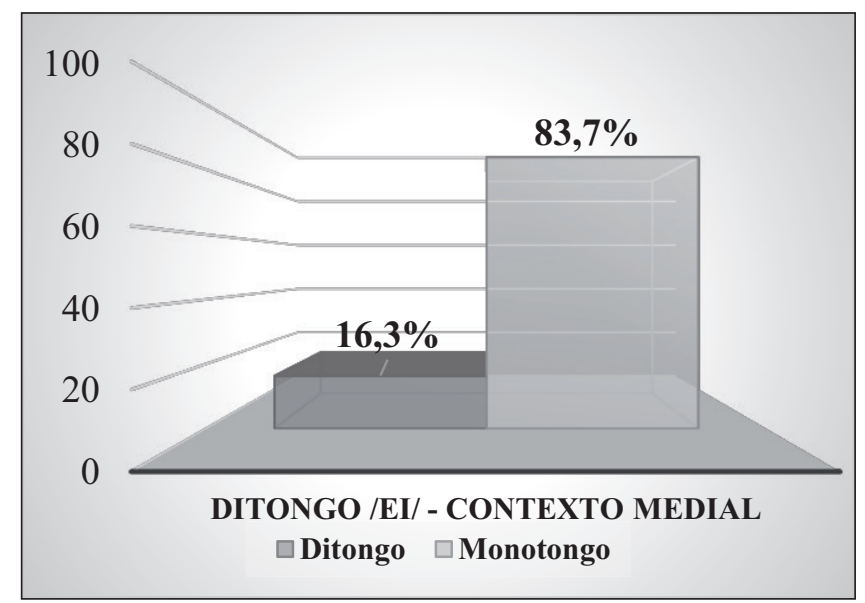

Figura 3 Percentuais de monotongação de /ei/ no PST(contexto medial de vocábulo)

Tabela 2 Ocorrências e percentuais de monotongação de /ei/ no PST (contexto medial de vocábulo)

\begin{tabular}{|l|c|c|}
\hline \multicolumn{1}{|c|}{ REALIZAÇÃo DE /ei/ } & OCo & $\%$ \\
\hline [ej] "dinh[ej]ro" & $68 / 417$ & 16,3 \\
\hline [e] "az[e]te" & $349 / 417$ & 83,7 \\
\hline
\end{tabular}

$\mathrm{Na}$ análise, duas variáveis mostraram-se atuantes para a queda da semivogal, sendo uma de caráter social, o nível de escolaridade, e uma de natureza estrutural, o contexto subsequente. A rodada que propiciou a análise teve significância .000 e input .91.

A primeira variável selecionada, escolaridade, demonstrou que há uma maior propensão à monotongação entre os falantes menos escolarizados, fator que apresentou um peso relativo bastante favorecedor, .81. Tal favorecimento decai conforme aumenta o índice de escolaridade dos falantes. Para o grupo intermediário, 
o P. R. foi de .32, já considerado desfavorecedor, e para o grupo de falantes de alta escolaridade o P. R. foi de .14, altamente desfavorecedor do fenômeno.

A Tabela 3 apresenta o número de ocorrências, percentuais e peso relativo de cada fator.

Tabela 3 Atuação da variável escolaridade sobre o processo de monotongação de /ei/ no PST em contexto medial de vocábulo

\begin{tabular}{|l|c|c|c|}
\hline \multicolumn{1}{|c|}{ FATORES } & OCO & PERC. & P. R. \\
\hline Fundamental & $\mathbf{1 7 9 / 1 8 4}$ & $\mathbf{9 7 . 3 \%}$ & $\mathbf{. 8 1}$ \\
\hline Médio & $111 / 138$ & $80.4 \%$ & .32 \\
\hline Superior & $59 / 95$ & $62.1 \%$ & .14 \\
\hline Input: .91 & \multicolumn{3}{|c|}{ Significância: .000 } \\
\hline
\end{tabular}

Tais resultados levam à conclusão de que, quanto maior o contato com a norma escrita, menor a probabilidade de o indivíduo cancelar, na fala, a semivogal. Na Figura 4, é possível observar a curva decrescente do índice de monotongação de acordo com o aumento da escolaridade.

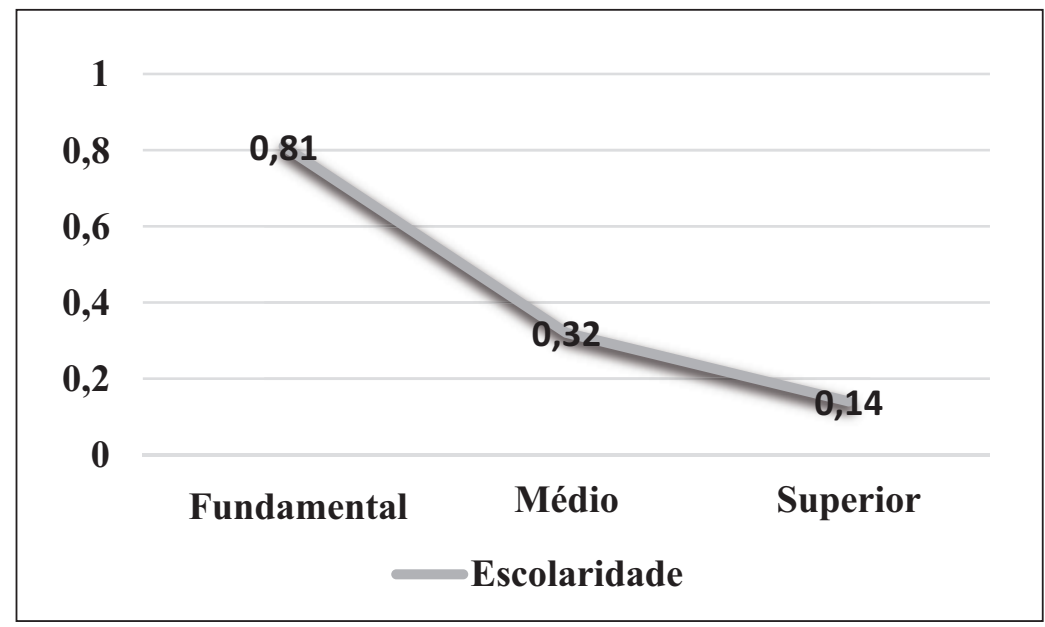

Figura 4 Atuação da variável nível de escolaridade sobre o processo de monotongação de /ei/ no PST em contexto medial de vocábulo

Este não foi o único trabalho que observou a atuação da variável escolaridade sobre o fenômeno da monotongação de /ei/. Em estudo sobre o PB, Lopes 
(2002) observou, além da atuação dos fatores estruturais, como a presença de um tepe e de uma consoante palatal no contexto subsequente, conforme exposto na seção 3.1 deste capítulo, a atuação da variável escolaridade, última variável selecionada em sua análise. Os resultados da autora demonstram um comportamento da escolaridade parecido com os que aqui apresentados, sendo os indivíduos mais escolarizados os que menos monotongam e os menos escolarizados os que mais produzem o fenômeno. Os pesos relativos encontrados por ela foram .66, para a faixa de escolaridade alta, .51, para a média, e .31 para a baixa.

Comportamento similar é também encontrado no trabalho de Silveira (2013) sobre o PST. No estudo do autor, a variável escolaridade foi a penúltima selecionada, e apresentou, da escolaridade mais alta à mais baixa, respectivamente, os pesos relativos .27, .48 e .64. Mais uma vez, quanto maior a escolarização, menor a incidência de queda da semivogal, o que reafirma que, de fato, parece que o contato com a norma escrita exerce influência sobre o fenômeno na fala.

A segunda variável selecionada como atuante sobre a monotongação em contexto medial foi, como dito, o contexto subsequente. Tal resultado estava dentro do esperado, devido ao apresentado nas seções anteriores, e os fatores atuantes como favorecedores do processo também foram os previstos: fricativas pós-alveolares e tepe. Seus pesos relativos foram, respectivamente, .67 e .59.

$\mathrm{Na}$ Tabela 4, expõem-se os resultados para cada fator da variável e, na Figura 5, destacam-se especificamente os pesos relativos.

Tabela 4 Atuação da variável contexto subsequente para a monotongação de /ei/ no PST (contexto medial de vocábulo)

\begin{tabular}{|c|c|c|c|c|}
\hline FATORES & OCO & PERC & P. R. & EXEMPLo \\
\hline$[r]$ & $241 / 268$ & $89.9 \%$ & .59 & mad[e]ra \\
\hline$\left[\int 3\right]$ & $45 / 47$ & $95.7 \%$ & .67 & $\begin{array}{l}\text { d[e]xo } \\
\text { f[e]jão }\end{array}$ \\
\hline$[t]$ & $56 / 86$ & $65.1 \%$ & .23 & f[e]tor (feitor) \\
\hline$[5$ z] & $5 / 12$ & $41.7 \%$ & .06 & ref[e]ção \\
\hline Outros segmentos & $2 / 4$ & $50 \%$ & .14 & mant[e]ga \\
\hline Input: .91 & \multicolumn{5}{|l}{} \\
\hline
\end{tabular}




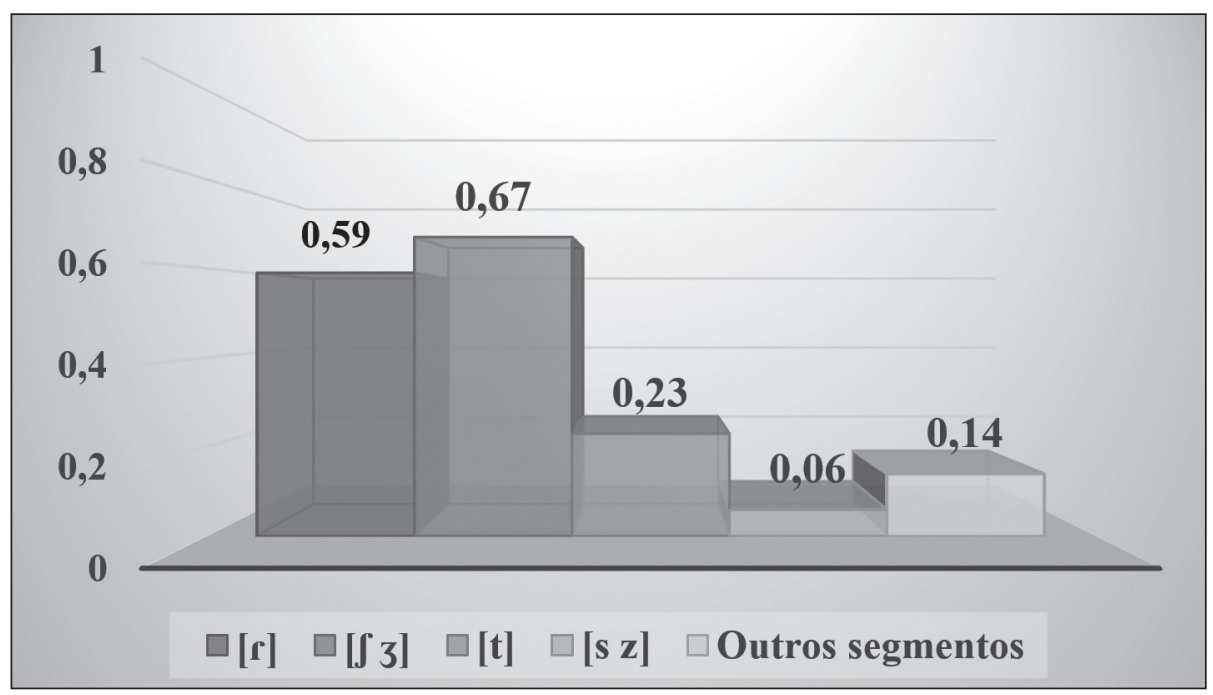

Figura 5 Atuação da variável contexto subsequente para a monotongação de /ei/ no PST, expressa só em pesos relativos (contexto medial de vocábulo)

O fator apontado como o maior favorecedor foram as fricativas pós-alverolares, com P. R.: .97 e o elevado percentual de monotongação de $95,7 \%$, o que representa 45 de 47 ocorrências, quase a totalidade. Podemos retomar as observações de Bisol (1989), que diz que diante de consoante palatal a inserção ou apagamento da semivogal não gera consequências para o significado da palavra, pois ela seria um espraiamento do traço [+alto] da palatal, gerando o chamado falso ditongo. $\mathrm{O}$ resultado deste trabalho parece reafirmar a posição da autora, o que também ocorre com o segundo fator selecionado como favorecedor, comentado a seguir.

O tepe teve peso relativo de .59 e percentual de $89,9 \%$, também bastante elevado, representando 241 ocorrências de um total de 268 . Bisol aponta que a monotongação nesse contexto igualmente não gera danos ao significado da palavra, sendo também um caso de falso ditongo, não presente na estrutura subjacente da sílaba, o que explica a elevada aplicação do fenômeno de queda da semivogal.

Quase todos os demais contextos funcionaram de maneira similar ao que ocorre no PB, ou seja, são desfavorecedores do processo. Eles foram divididos em fricativas alveolares e outros segmentos, que compreendeu apenas 4 ocorrências, sendo um de [n] (“treinarem"), uma de [f] (“gaseificados"), uma de [d] (“Almeida) e uma de [g] ("leigo"). Os pesos relativos desses fatores foram, respectivamente, .06 e .14. A exceção para essa semelhança foi a presente de um [t] no contexto subsequente.

Embora, a princípio, se observado apenas o P. R., que foi de .23, tal contexto se mostre desfavorecedor, se se observa o percentual de ocorrência do processo, 
que foi de $65,1 \%$, representando 56 de 86 dados, verifica-se que a monotongação de /ei/ pode ocorrer diante de [t] no PST, o que não ocorre no $\mathrm{PB}$, indicando uma divergência entre as duas variedades.

\subsection{O ditongo /ei/ em contexto final}

Os resultados para a análise do ditongo /ei/ em contexto final em formas verbais apresentaram o índice percentual mais baixo em comparação ao índice geral e ao do contexto medial, tendo a monotongação ocorrido em 52, 5\% dos dados, como demonstram o gráfico e a tabela a seguir.

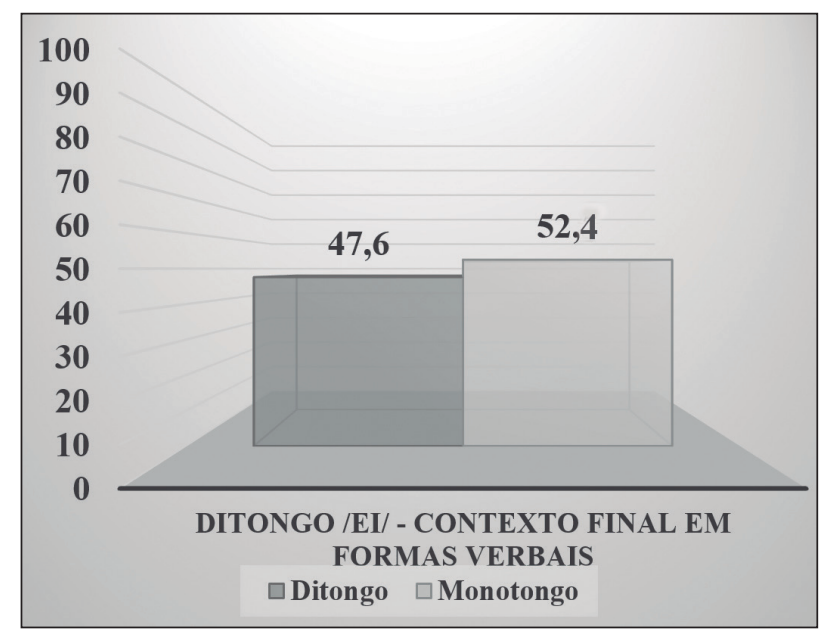

Figura 6 Percentuais de monotongação de /ei/ no PST (contexto final em formas verbais)

Tabela 5 Ocorrências e percentuais de monotongação de /ei/ no PST (contexto final em formas verbais)

\begin{tabular}{|l|c|c|}
\hline \multicolumn{1}{|c|}{ REALIZAÇÃo DE /ei/ } & OCO & $\%$ \\
\hline [ej] "deixei" & $152 / 319$ & 47,6 \\
\hline [e] "fiquê" & $167 / 319$ & 52,4 \\
\hline
\end{tabular}

Ainda que o percentual seja mais equilibrado, é possível afirmar que a monotongação em contexto final em formas verbais ocorre no PST, diferentemente do que se observa do PB. Paiva (1996), como já se salientou, não chega a considerar o contexto final em seu estudo pois considera que a manutenção da semivogal nesse contexto seria categórica, fato que pode ser observado também no trabalho de Ribeiro (1990), que, ao analisar a variável tipo de sílaba, dividida entre os fa- 
tores não final e final, encontrou como resultado $0 \%$ de queda da semivogal nesta última. Assim, este caso constitui um traço divergente do PST em relação ao $\mathrm{PB}$.

A única variável apontada pelo Programa Goldvarb-X como atuante para o processo foi frequência de uso de um crioulo. Os resultados demonstraram que o fator frequência alta seria o grande favorecedor da queda da semivogal, com P. R.: .93. Já para as frequências média e baixa os pesos relativos estão próximos da neutralidade, ainda que esta última tenha um índice um pouco mais inibidor, .48 e .43, respectivamente. $\mathrm{O}$ total de ocorrências e percentuais de monotongação por fator são apresentados na Tabela 6.

Tabela 6 Atuação da variável frequência de uso de um crioulo para a monotongação de /ei/ no PST (contexto final em formas verbais)

\begin{tabular}{|l|c|c|c|}
\hline \multicolumn{1}{|c|}{ FATORES } & OCO & PERC. & P. R. \\
\hline Baixa & $78 / 164$ & $47.6 \%$ & .43 \\
\hline Média & $71 / 136$ & $52.2 \%$ & .48 \\
\hline Alta & $\mathbf{1 8 / 1 9}$ & $\mathbf{9 4 . 7 \%}$ & .93 \\
\hline Input: .54 Significância: .000 \\
\hline
\end{tabular}

Cabe lembrar que a variável foi formulada com base na hipótese de que quanto maior uso um indivíduo fizesse de um crioulo, mais sua fala estaria sujeita a influências dessa língua e, consequentemente, mais se afastaria da norma do PE. Ferraz (1979) apresenta um estudo sobre o Forro, no qual, além de tratar da sua formação, apresenta as suas principais características fonológicas e gramaticais.

$\mathrm{O}$ autor demonstra que o principal padrão silábico do Forro é do tipo $\mathrm{CV}$, seguido dos padrões V e CVC, sendo este menos usual que o anterior. Segundo ele, a estrutura da sílaba do Forro apresenta uma simplificação com relação à do PE, pois no Forro a sílaba é predominantemente aberta, sendo os casos de sílaba fechada, no padrão CVC, uma influência do Português.

O autor afirma, no entanto, que, no Forro, o onset da sílaba pode ser constituído por uma sequência de até três segmentos consonantais. No caso de uma sequência de duas consoantes, a segunda equivaleria a /// ou a uma semivogal, havendo também a possibilidade de a primeira consoante ser uma homorgânica nasal, como no exemplo apresentado pelo autor " $n d a$ "(andar). Já os casos em que o onset apresenta três consoantes seriam bem específicos: “(...) C1 seria sempre igual a uma fricativa sibiliante surda, C2 a [t] ou [k], e C3 a /l/" (1979, p. 27). 
Ainda em relação ao resultado da análise aqui apresentada, uma observação se faz necessária. Apenas um dos informantes da pesquisa declarou fazer alto uso do Forro. Portanto, todos os dados referentes ao fator alta frequência, que apresentou um total de 19 ocorrências, das quais 18 com queda da semivogal, pertencem ao mesmo indivíduo, da faixa etária mais alta e de menor nível de escolaridade, fator este que, em contexto medial, se mostrou favorecedor da monotongação.

Apesar do exposto, o resultado não contraria a hipótese formulada, ao contrário, mostra evidências de que, em análises futuras, com um corpus ampliado e um maior número de informantes com o mesmo perfil, resultado semelhante poderá ser encontrado.

Por fim, ainda que essa variável tenha sido a única selecionada pelo programa, vale a pena mencionar o resultado referente à variável nivel de escolaridade. Em termos percentuais, observa-se a mesma curva decrescente obtida na análise do contexto medial, sendo os indivíduos menos escolarizados os que mais aplicam a monotongação, seguidos pelos da faixa intermediária e pelos da faixa alta, com percentuais de $60,6 \%, 50 \%$ e $46,2 \%$, respectivamente. Isso parece indicar que realmente há a influência dessa variável na fala da comunidade estudada.

\section{CONSIDERAÇÕES FINAIS}

Neste estudo apresentaram-se os resultados da dissertação de Passos (2018) sobre a realização do ditongo /ei/ na variedade urbana do PST, na qual se demonstra que a monotongação é um processo produtivo e constitui uma regra variável na comunidade.

As restrições que favorecem a aplicação dessa regra variam segundo a posição da sílaba no vocábulo. Em posição medial, é condicionada pelo nível de escolaridade e o contexto subsequente, sendo os indivíduos menos escolarizados os que mais a implementam, sobretudo quando o ditongo é seguido por fricativa palato alveolar ou por tepe. Em contexto final, verificou-se que indivíduos que se utilizam do Forro, com alta frequência, em suas práticas intercomunicativas são os mais suscetíveis à monotongação.

Os resultados demonstraram haver convergências entre as variedades urbanas do PST e do PB quanto ao contexto medial, apesar de no PB a monotongação não ocorrer diante de [t]. Já com relação ao contexto final, observa-se divergência, uma vez que a monotongação nessa posição não é típica no PB.

Por fim, espera-se que este estudo possa contribuir para o conhecimento dessa variedade africana do Português, conhecendo-a um pouco mais do ponto de vista fonético-fonológico, e, assim, contribuir também para o conhecimento do PB. 


\section{REFERÊNCIAS}

AVELAR, Juanito; GALVES, Charlotte. O papel das línguas africanas na emergência da gramática do português brasileiro. Linguística, 30 (2), diciembre 2014: 241-288.

BISOL, Leda. O ditongo na perspectiva da fonologia atual. Revista DELTA, São Paulo, v. 05, n. 2, p. 185-224, 1989.

BISOL, Leda. Ditongos derivados. Revista DELTA, v. 10, n. especial, p. 123-140, 1994.

BISOL, Leda. Ditongos derivados: um adendo. In: LEE, S. H. (Org.). Vogais além de Belo Horizonte. Belo Horizonte: FALE/UFMG, 2012.

BRANDÃO, Silvia Figueiredo. Concordância nominal na variedade não standard do português falado em São Tomé. Comunicação apresentada ao XVI Congresso Internacional de ALFAL, Alcalá de Henares, Espanha. Universidad de Alcalá, 6-9 jun., 2011.

BRANDÃO, Silvia Figueiredo. Patterns of plural agreement within the Noun Phrase. Journal of Portuguese Linguistics, 12 (2): 51-100, 2013.

BRANDÃO, Silvia Figueiredo; VIEIRA, Silvia Rodrigues. A concordância nominal e verbal no Português do Brasil e no Português de São Tomé: uma abordagem sociolinguística. Papia: Revista Brasileira de Estudos Crioulos e Similares, v. 22, n. 1, p. 7-39, 2012.

CALLOU, Dinah; LEITE, Yonne. Iniciação à fonética e à fonologia. 11. ed. Rio de Janeiro: Zahar, 2009. [1990].

CÂMARA JR., Joaquim Mattoso. Estrutura da Lingua Portuguesa. 44. ed. Rio de Janeiro: Vozes, 2011. [1970].

CINTRA, Lindley. Estudos de dialectologia portuguesa. Lisboa: Sá da Costa, 1983.

CUNHA, Celso. Conservação e inovação no Português do Brasil. O Eixo e a Roda. Belo Horizonte, 5: 199-230, 1986.

FERRAZ, Luiz Ivens. The creole of São Tomé. Johannesburg: Witwatersrand University Press, 1979.

GONÇALVES, C. A. V. Ditongos decrescentes: variação \& ensino. Revista de Estudos da Linguagem. Belo Horizonte: Faculdade de Letras da UFMG, v. 6. n. 5. p. 159-192, jan./jun. 1997.

GONÇALVES, C. A. V.; COSTA, R. G. R. Sobre a interpretação fonológica dos ditongos em português. In: IV Congresso da Assel-Rio, 1995, Niterói. Anais do IV Congresso da Assel-Rio. Niterói: Assel-Rio, 1994. v. 1. p. 76-85.

LABOV, William. Padrões sociolinguísticos. Trad.: Marcos Bagno; Marta Scherre e Caroline Cardoso. São Paulo: Parábola, 2008. [1972].

LABOV, W. Principles of linguistic change: internal factors. Oxford: Blackwell Publishers, 1994. v. 1.

LABOV, W. Principles of linguistic change: social factors. Oxford: Blackwell Publishers, 2001. v. 2. 
LOPES, Raquel. A realização variável dos ditongos /ow/ e /ej/ no português falado em Altamira/PA. 97 f. Dissertação (Mestrado em Linguística), UFPA, Belém, PA, 2002.

MATEUS, Maria Helena Mira; D’ANDRADE, Ernesto.The phonology of portuguese. Oxford: University Press, 2000.

PAIVA, M. C. A. Supressão das semivogais nos ditongos decrescentes. In: SIlVA, G. M. O.; SCHERRE, M. M. P. (Org.). Padrões sociolinguísticos. Rio de Janeiro: Tempo Brasileiro, 1996a. p. 217-236.

PAIVA, M. C. A. O percurso da monotongação de [ey]: observações no tempo real. In: PAIVA, M. C.; DUARTE, M. E. L. (Org.). Mudança linguística em tempo real. Rio de Janeiro: Contra Capa, 2011. p. 31-46.

PASSOS, R. R.; BARCELOS, N. H. M. O ditongo /ei/ na fala do Português de São Tomé. Comunicação apresentada à XXXVII Jornada de Iniciação Científica da UFRJ. Faculdade de Letras, 2015.

PASSOS, R. R. O Ditongo leil na variedade urbana do Português de São Tomé. 2018. 88 fls. Dissertação de Mestrado em Letras Vernáculas, Língua Portuguesa. Faculdade de Letras, Universidade Federal do Rio de Janeiro, 2018.

PEREIRA, Gerusa. Monotongação dos ditongos laj/, lej/, low/ no Português falado em Tubarão (SC): estudo de casos. Dissertação (Mestrado em Ciências da Linguagem) Tubarão-SC, Universidade do Sulde Santa Catarina, 2004. 134f.

PETTER, Margarida Maria Taddoni. Uma hipótese explicativa do contato entre o português e as línguas africanas. Revista Papia, 17: 9-19, 2007.

RIBEIRO, Denise Aparecida Sofiati de Barros. O apagamento dos ditongos decrescentes orais no sudoeste do Paraná. Dissertação (Mestrado em Linguística), UFPR, Curitiba, 1990. $125 \mathrm{f}$.

SILVA, Vanessa Meireles de Oliveira. Analyse phonologique et métrique des glides et diphtongues en portugais brésilien. Thèse de Doctorat. Paris: Université Paris 8 Vincennes - Saint-Denis, 2014.

SILVEIRA, A. C. Ditongos no Português de São Tomé e Príncipe. 2013. 180fls. Dissertação (Mestrado em Filologia e Língua Portuguesa). Faculdade de Filosofia, Letras e Ciências Humanas, Universidade de São Paulo, 2013.

TOLEDO, Eduardo Elisal de. 2011. 109f. A monotongação do ditongo decrescente [ej] em amostra de recontato de Porto Alegre. Dissertação (Mestrado em Linguística), PUCRS, Porto Alegre, RS, 2011.

VIEIRA, S. R.; BAZENGA, A. M. Patterns of 3rd person verbal agreement. Journal of Portuguese Linguistics, v. 12, p. 7-50, 2013.

WEINREICH, U.; LABOV, W.; HERZOG, M. Empirical foundations for a theory of linguistic change. In: LEHMANN, W.; MALKIEL, Y. (Org.). Directions for historical linguistics. Austin: University of Texas Press, 1968. p. 97-195. 